\title{
The impact on survival of positive intraoperative pleural lavage cytology in patients with non-small-cell lung cancer
}

\author{
Keiju Aokage, MD, ${ }^{\mathrm{a}}$ Junji Yoshida, MD, ${ }^{\mathrm{a}}$ Genichiro Ishii, MD, ${ }^{\mathrm{b}}$ Sotarou Enatsu, MD, ${ }^{\mathrm{a}}$ \\ Tomoyuki Hishida, MD, ${ }^{\mathrm{a}}$ Mitsuyo Nishimura, MD, ${ }^{\mathrm{a}}$ Yutaka Nishiwaki, MD, ${ }^{\mathrm{a}}$ and Kanji Nagai, MD
}

Objective: The aim of this study was to analyze intraoperative pleural lavage cytology results in patients with non-small-cell lung cancer and quantify the impact on survival and recurrence.

\begin{abstract}
Methods: From August 1992 through November 2006, pleural lavage cytology results before and after lung resection were both available in 2178 patients with non-small-cell lung cancer. We assessed the pre-pleural lavage cytology impact on survival, comparing with 9 factors available before lung resection by multivariate analyses. We also compared the impact with that of pleural dissemination or malignant pleural effusion. For post-pleural lavage cytology, we analyzed its survival impact in relation with 15 clinicopathologic factors, including those available after resection, by multivariate analyses.
\end{abstract}

Results: Pre-pleural lavage cytology proved to be a strong independent prognostic factor, but the 5-year survival rate was $37 \%$ in 65 patients without dissemination but with a positive pre-pleural lavage cytology, which was significantly higher than $12 \%$ in 86 patients with dissemination. When factors available after resection were combined, post-pleural lavage cytology showed a stronger survival impact than pre-pleural lavage cytology. Postpleural lavage cytology was also a strong predictor of recurrence. The positive post-pleural lavage cytology group had a marginally, but not significantly, better survival compared with the malignant pleural effusion group. Almost all patients with positive post-pleural lavage cytology relapsed within 5 years.

Conclusions: Pre-pleural lavage cytology is of less use in clinical practice. Post-pleural lavage cytology was a very strong independent prognostic factor, and almost all patients with positive post-pleural lavage cytology relapsed within 5 years. We propose that positive post-pleural lavage cytology disease should be classified to pathologic T4 and managed similarly to dissemination. (J Thorac Cardiovasc Surg 2010;139:1246-52)

O Supplemental material is available online.

\section{Earn CME credits at}

http://cme.ctsnetjournals.org
Although many researchers have reported on pleural lavage cytology (PLC) for non-small-cell lung cancer (NSCLC) since $1958,{ }^{1}$ the comparative significance of PLC immediately after thoracotomy (pre-PLC) and that before chest clo-

\footnotetext{
From the Department of Thoracic Oncology ${ }^{\mathrm{a}}$ and the Pathology Division, Research Center for Innovative Oncology, ${ }^{\mathrm{b}}$ National Cancer Center Hospital East, Kashiwa, Chiba, Japan.

This study was supported in part by a Grant-in-Aid for Cancer Research from the Ministry of Health, Labour and Welfare, Japan.

Disclosures: None.

Received for publication Oct 23, 2008; revisions received June 9, 2009; accepted for publication July 16, 2009; available ahead of print Sept 18, 2009.

Address for reprints: Junji Yoshida, MD, PhD, Division of Thoracic Surgery, National Cancer Center Hospital East, 6-5-1 Kashiwanoha, Kashiwa, Chiba, 277-8577, Japan (E-mail: jyoshida@east.ncc.go.jp).

$0022-5223 / \$ 36.00$

Copyright (c) 2010 by The American Association for Thoracic Surgery doi: $10.1016 /$ j.jtcvs.2009.07.049
}

sure (post-PLC) and their implication in clinical practice have not been fully understood. In 2006, we reported an analysis on pre- and post-PLC in a large cohort of almost 1200 patients. $^{2}$ We concluded that positive post-PLC result had a greater and independent impact on survival and should be incorporated in the pathologic staging of NSCLC. We continued accumulating patients, and the number of patients has more than doubled in 5 years. Based on this large singleinstitution cohort, we reevaluated the impact of PLC on survival of patients with resected NSCLC to establish its significance in clinical practice.

\section{METHODS}

From July 1992 through November 2006, 2866 patients had surgical resection for primary NSCLC at the National Cancer Center Hospital East, including exploratory thoracotomy and palliative resections. We have prospectively performed intraoperative PLC in all patients without pleural effusion or dissemination since July 1992, when it was approved for this observational study by the institutional review board. In this study, we evaluated only patients who had complete resection by more than lobectomy and systematic lymph node dissection. Histologic diagnosis was obtained by preoperative bronchofiberscopic biopsy, needle biopsy guided by computed tomography scan, or intraoperative biopsy. Histologic typing was determined according to the World Health Organization classification. ${ }^{3}$ We excluded patients with low-grade malignancy from this study. Disease stages were determined based on the TNM classification of the International Union Against Cancer. ${ }^{4}$ 


\section{Abbreviations and Acronyms \\ CEA = carcinoembryonic antigen \\ NSCLC $=$ non-small-cell lung cancer \\ PLC = pleural lavage cytology}

Immediately after thoracotomy, the pleural cavity was carefully observed and washed with $500 \mathrm{~mL}$ physiologic saline solution before any pulmonary parenchyma manipulation if there was no pleural effusion or apparent dissemination. A sample of $50 \mathrm{~mL}$ was retrieved for cytologic evaluation (pre-PLC). Lobectomy, bilobectomy, or pneumonectomy, ensuring complete en bloc tumor removal, was performed, followed by systematic lymph node dissection without tumor exposure. Before chest closure, a pleural cavity lavage sample was also retrieved (post-PLC) in the same fashion. Samples were centrifuged at $1500 \mathrm{rpm}$ for 5 minutes. The sediment was stained using the Papanicolaou method. A single cytologist blinded to the clinicopathologic information evaluated the specimens and classified them into 5 categories (classes I-V). The results were dichotomized as negative for classes I to III and as positive for classes IV and V.

\section{Pre-PLC}

We assessed the survival impact of the following prognostic factors available before lung resection including pre-PLC results: age, sex, smoking history, preoperative serum carcinoembryonic antigen (CEA) level $(<5.0$ $\mathrm{ng} / \mathrm{mL}$ vs $\geq 5.0 \mathrm{ng} / \mathrm{mL}$ ), pre-PLC, clinical T classification, clinical $\mathrm{N}$ classification, clinical stage (univariate analysis only), and surgical (gross) pleural involvement by univariate and multivariate analyses. We defined $\mathrm{cN} 2$ as mediastinal lymph node(s) greater than $1.0 \mathrm{~cm}$ in the shortest dimension on preoperative conventional computed tomography scan. Pleural involvement was classified according to the Japan Lung Cancer Society criteria ${ }^{5}$ : p0, tumor did not extend beyond the elastic pleural layer; p1, tumor extended beyond the elastic layer but was not exposed on the pleural surface; $\mathrm{p} 2$, tumor was exposed on the pleural surface; and p3, tumor invaded the parietal pleura or chest wall. Surgeons determined pleural involvement
( $\mathrm{sP}$ factor) based on the gross findings before resection. We also compared survival between patients with dissemination and those without dissemination but with a positive pre-PLC result to clarify whether positive pre-PLC results contraindicate surgical resection or not.

\section{Post-PLC}

For post-PLC, the following factors were analyzed to investigate the impact on patient survival and recurrence by univariate and multivariate analyses: age, sex, smoking history, preoperative serum CEA level $(<5.0 \mathrm{ng} / \mathrm{mL}$ vs $\geq 5.0 \mathrm{ng} / \mathrm{mL}$ ), resection type (lobectomy or bilobectomy vs pneumonectomy), histology (adenocarcinoma vs others), differentiation (well differentiated vs moderately or poorly differentiated), pathologic $\mathrm{T}$ classification, pathologic $\mathrm{N}$ classification, pathologic stage (univariate analysis only), pathologic pleural involvement, lymphatic permeation (negative vs positive), vascular invasion (negative vs positive), pre-PLC result (negative vs positive), and post-PLC result (negative vs positive). Pathologic pleural involvement ( $\mathrm{p}$ factor) was diagnosed on the resected specimens by a single pathologist blinded to the clinical and surgical findings. Lymphatic permeation and vascular invasion indicated tumor cells identifiable in the lymphatic and vascular vessel lumen, respectively.

The length of overall survival was defined as the interval in months between the day of surgical intervention and the date of death due to any cause or the last follow-up. Also, the length of recurrence-free survival was defined as the interval in months between the date of surgical intervention and lung cancer recurrence. An observation was censored at the last follow-up when the patient was alive or lost to follow-up.

\section{Statistical Analysis}

Differences in patient characteristics between the 2 populations were tested for significance using Pearson chi-square test or Fisher exact test. For univariate analyses, all cumulative survival rates were estimated by the Kaplan-Meier method, and differences in variables were calculated by the log-rank test. Multivariate analyses were performed using the Cox proportional hazards model. Forward and backward stepwise procedures were used to determine the combination of prognostic factors. All $P$ values reported are 2-sided. The analyses were performed with the SPSS 11.0

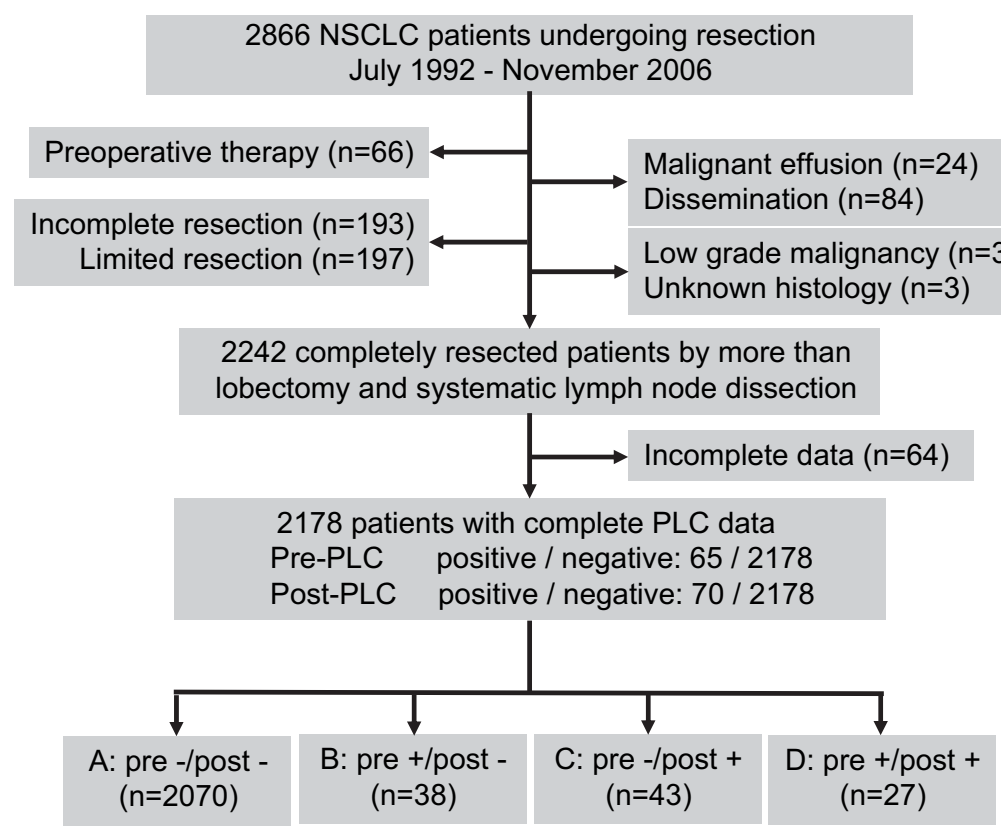

FIGURE 1. Patients enrolled in the study. NSCLC, Non-small-cell lung cancer; $P L C$, pleural lavage cytology. 
TABLE 1. Univariate analysis on prognostic factors available before lung resection

\begin{tabular}{|c|c|c|}
\hline Factors & $\mathbf{n}$ & $P$ value \\
\hline \multicolumn{3}{|l|}{ Age $(y)^{*}$} \\
\hline$<66$ & 1086 & \\
\hline$\geq 66$ & 1093 & $<.001$ \\
\hline \multicolumn{3}{|l|}{ Sex } \\
\hline Male & 1387 & \\
\hline Female & 792 & $<.001$ \\
\hline \multicolumn{3}{|l|}{ Smoking history } \\
\hline Never smoker & 687 & \\
\hline Current/previous smoker & 1473 & $<.001$ \\
\hline \multicolumn{3}{|l|}{ CEA level (ng/mL) } \\
\hline$<5.0$ & 1287 & \\
\hline$\geq 5.0$ & 876 & $<.001$ \\
\hline \multicolumn{3}{|l|}{ Pre-PLC } \\
\hline Positive & 65 & \\
\hline Negative & 2113 & $<.001$ \\
\hline \multicolumn{3}{|l|}{ Clinical T classification } \\
\hline $\mathrm{cT} 1$ & 1154 & $<.001$ \\
\hline $\mathrm{cT} 2$ & 871 & \\
\hline cT3 & 123 & \\
\hline cT4 & 31 & \\
\hline \multicolumn{3}{|l|}{ Clinical $\mathrm{N}$ classification } \\
\hline $\mathrm{cNO}$ & 1898 & $<.001$ \\
\hline $\mathrm{cN} 1$ & 197 & \\
\hline $\mathrm{cN} 2$ & 84 & \\
\hline \multicolumn{3}{|l|}{ Clinical stage } \\
\hline I & 1801 & $<.001$ \\
\hline II & 221 & \\
\hline III & 147 & \\
\hline IV & 10 & \\
\hline \multicolumn{3}{|l|}{ Surgical pleural involvement } \\
\hline sP0 & 1088 & $<.001$ \\
\hline sP1 & 797 & \\
\hline $\mathrm{sP} 2$ & 81 & \\
\hline sP3 & 213 & \\
\hline
\end{tabular}

$C E A$, Carcinoembryonic antigen; $P L C$, pleural lavage cytology. *Age was dichotomized by median age: 66 years.

statistical software program (Dr. SPSS II for Windows, standard version 11.0, SPSS Inc, Chicago, Ill) and GraphPad Prism statistical software program (Prism for Windows, Version 5.02, GraphPad Software, Inc, La Jolla, Calif).

Data collection and analyses were approved and the need for obtaining informed consent from each patient was waived by the institutional review board in June 2007.

\section{RESULTS}

Among the 2866 patients who had surgical resection for primary NSCLC, we excluded 688 patients for various reasons (Figure 1). For the remaining 2178 patients whose pre- and post-PLC data were both available, statistical analyses were performed. Sixty-five (3.0\%) patients had a positive pre-PLC result and $70(3.2 \%)$ had a positive post-PLC result. At the time of this analysis, the median follow-up for all patients was 54 months (range, 1-162 months).
TABLE 2. Multivariate analysis for prognostic factors available before lung resection

\begin{tabular}{|c|c|c|}
\hline Variables & $\begin{array}{c}\text { Hazard ratio } \\
(\mathbf{9 5} \% \mathbf{C I})\end{array}$ & $\begin{array}{c}P \\
\text { value }\end{array}$ \\
\hline Age $(\geq 66$ vs $<66)$ & $1.609(1.392-1.861)$ & $<.001$ \\
\hline Smoking history (smoker vs never) & $1.469(1.157-1.865)$ & .002 \\
\hline CEA level $(<5.0 \mathrm{ng} / \mathrm{mL}$ vs $\geq 5.0 \mathrm{ng} / \mathrm{mL})$ & $1.442(1.244-1.671)$ & $<.001$ \\
\hline $\begin{array}{l}\text { Clinical T classification } \\
\text { cT1 }\end{array}$ & & $<.001$ \\
\hline cT2 & $1.488(1.271-1.742)$ & $<.001$ \\
\hline cT3 & $1.228(0.903-1.670)$ & .190 \\
\hline cT4 & $2.033(1.234-3.351)$ & .005 \\
\hline $\begin{array}{l}\text { Clinical N classification } \\
\mathrm{cN} 0\end{array}$ & & .001 \\
\hline $\mathrm{cN} 1$ & $1.344(1.069-1.689)$ & .011 \\
\hline $\mathrm{cN} 2$ & $1.603(1.205-2.133)$ & .001 \\
\hline $\begin{array}{l}\text { Surgical pleural involvement } \\
\text { sP0 }\end{array}$ & & .001 \\
\hline sP1 & $1.114(0.951-1.306)$ & .182 \\
\hline $\mathrm{sP} 2$ & $1.290(0.917-1.816)$ & .144 \\
\hline sP3 & $1.575(1.256-1.975)$ & $<.001$ \\
\hline Pre-PLC (positive vs negative) & $2.350(1.724-3.203)$ & $<.001$ \\
\hline
\end{tabular}

\section{Factors Available Before Lung Resection}

Univariate analysis results for prognostic factors available before lung resection including pre-PLC are shown in Table 1. Significant differences in survival were observed for the following factors: age, sex, smoking history, preoperative serum CEA level, clinical $\mathrm{T}$ classification, clinical $\mathrm{N}$ classification, clinical stage, surgical pleural involvement, and pre-PLC result. Among these factors, multivariate analysis identified the following 7 factors as independently prognostic: age, smoking history, preoperative serum CEA level, clinical $\mathrm{T}$ classification, clinical $\mathrm{N}$ classification, surgical pleural involvement, and pre-PLC result (Table 2).

The 5-year survival rate was $37 \%$ in 65 patients without dissemination but with a positive pre-PLC result, which was significantly higher than $12 \%$ in 86 patients with dissemination $(P=.002$; Figure $2, A)$.

\section{Including Factors Available After Lung Resection}

The $22 \%$ overall and $4 \%$ recurrence-free survival rates at 5 years for patients with positive post-PLC were significantly worse than $69 \%$ and $67 \%$ for patients with negative post-PLC, respectively $(P<.001$; Figure 3$)$. Only $1(1.4 \%)$ among 70 patients with positive post-PLC survived without recurrence for more than 5 years.

Univariate analyses on overall and recurrence-free survival revealed significant difference for 15 clinicopathologic factors analyzed including data available after lung resection (Table E1; this item is online only). Among these factors, excluding pathologic stage, multivariate analysis for factors predictive of overall survival revealed the following 9 
A

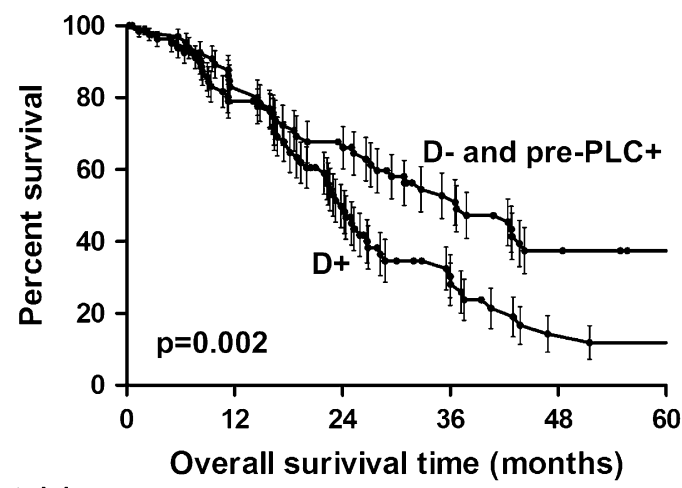

Patients at risk

$\begin{array}{ccccccc}\text { D- and pre-PLC+ } & 65 & 55 & 44 & 28 & 20 & 17 \\ \text { D+ } & 86 & 59 & 33 & 14 & 7 & 6\end{array}$

B

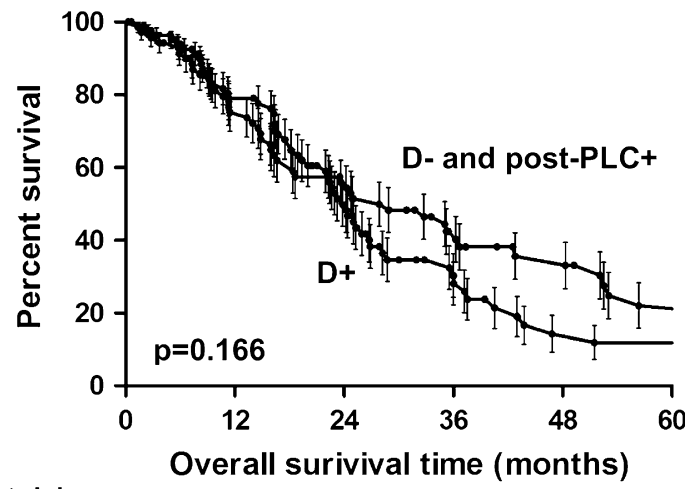

Patients at risk

D- and post-PLC+ D+

$\begin{array}{llllcl}70 & 51 & 37 & 20 & 14 & 8 \\ 86 & 59 & 33 & 14 & 7 & 6\end{array}$

FIGURE 2. A, Survival curves of patients with dissemination and/or malignant effusion (D+) and patients with positive pre-PLC without dissemination/malignant effusion ( $\mathrm{D}-$ and pre-PLC + ). Survival was significantly better in D- and pre-PLC+ group (5-year survival rate: 37\%) than in D+ group $(11 \% ; P=.002)$. B, Survival curves of patients with dissemination and/or malignant effusion (D+) and patients with positive post-PLC without dissemination and/or malignant effusion ( $\mathrm{D}-$ and post-PLC+). Survival rates did not differ significantly between the 2 groups $(P=.166)$. The fine vertical bars in each graph indicate the standard error for each data point. $P L C$, Pleural lavage cytology.

variables as independently prognostic: age, preoperative serum CEA level, pathologic $\mathrm{T}$ classification, pathologic $\mathrm{N}$ classification, pathologic pleural involvement, lymphatic permeation, vascular invasion, and pre-PLC and post-PLC results (Table 3 ). The multivariate analysis for factors predictive of recurrence-free survival revealed the following 9 variables as independently prognostic: age, differentiation, pathologic $\mathrm{T}$ classification, pathologic $\mathrm{N}$ classification, pathologic pleural involvement, lymphatic permeation, vascular invasion, and pre-PLC and post-PLC results (Table 4). The prognostic hazard ratio of post-PLC for overall survival was higher at 1.769 than that of pre-PLC at 1.544. The hazard ratio of post-PLC for recurrence was the highest at 2.552 among the clinicopathologic factors other than $\mathrm{pN} 2$ or $\mathrm{pN} 3$.
A

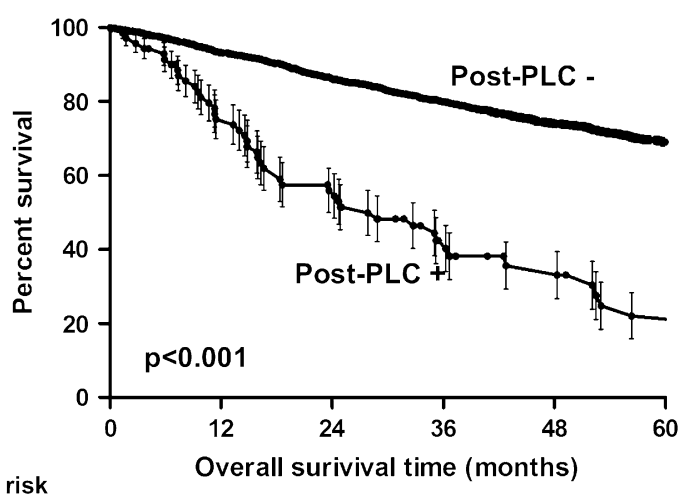

\begin{tabular}{ccccccc} 
Patients at risk & \multicolumn{7}{c}{ Overall surivival time (months) } \\
post-PLC- & 2108 & 1955 & 1762 & 1458 & 1200 & 968 \\
post-PLC+ & 70 & 52 & 38 & 21 & 15 & 9
\end{tabular}

B

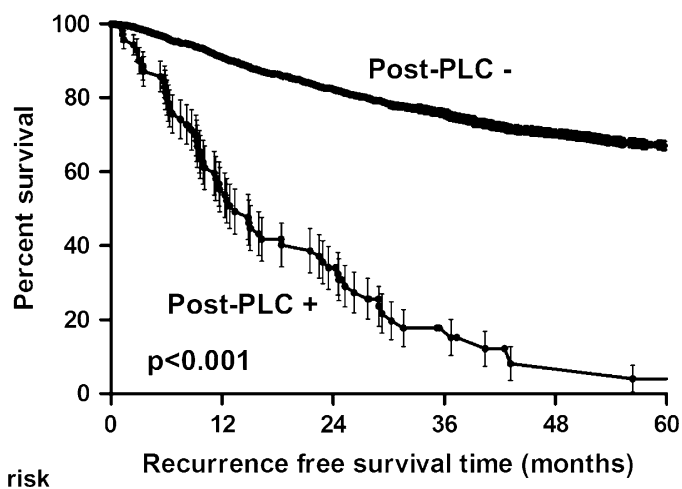

Patients at risk

$\begin{array}{lcccccc}\text { post-PLC- } & 2106 & 1862 & 1622 & 1314 & 1084 & 758 \\ \text { post-PLC+ } & 70 & 37 & 22 & 7 & 2 & 1\end{array}$

FIGURE 3. A, Overall survival curves of patients according to post-PLC results. The $22 \% 5$-year survival rate for patients with positive post-PLC was significantly worse than $69 \%$ for patients with negative post-PLC $(P<.001$, log-rank test). B, Recurrence-free survival curves of patients according to post-PLC results. The $4 \% 5$-year recurrence-free survival rate for patients with positive post-PLC was much worse than the $67 \%$ for patients with negative post-PLC $(P<.001, \log$-rank test). The fine vertical bars in each graph indicate the standard error for each data point. $P L C$, Pleural lavage cytology.

The difference in cumulative survival between patients without dissemination but with a positive post-PLC result and those with dissemination was not statistically significant $(P=.166$; Figure 2, $B)$.

The Kaplan-Meier curves of the following 4 groups are shown in Figure 4: pre-PLC-/post-PLC-, pre-PLC+/postPLC-, pre-PLC-/post-PLC + , pre-PLC + /post-PLC+. The survivals were similarly poor for positive post-PLC groups regardless of pre-PLC results and were significantly worse than negative post-PLC groups.

\section{DISCUSSION}

PLC in patients with NSCLC was first reported by Spjut and colleagues in $1958,{ }^{1}$ and its result was reported to be a possible prognostic factor in NSCLC patients who had 
TABLE 3. Multivariate analysis for factors predictive of overall survival

\begin{tabular}{lcr}
\hline \multicolumn{1}{c}{ Variables } & $\begin{array}{c}\text { Hazard ratio } \\
(\mathbf{9 5} \% \mathbf{C I})\end{array}$ & $\begin{array}{r}\boldsymbol{P} \\
\text { value }\end{array}$ \\
\hline Age $(\geq 66 \mathrm{vs}<66)$ & $1.676(1.444-1.947)$ & $<.001$ \\
CEA level $(<5.0 \mathrm{ng} / \mathrm{mL}$ vs $\geq 5.0 \mathrm{ng} / \mathrm{mL})$ & $1.213(1.043-1.411)$ & .012 \\
Pathologic T classification & & $<.001$ \\
pT1 & & \\
pT2 & $1.524(1.264-1.837)$ & \\
pT3 & $1.227(0.843-1.788)$ & \\
pT4 & $1.655(1.258-2.179)$ & \\
Pathologic N classification & & $<.001$ \\
pN0 & & \\
pN1 & $1.726(1.408-2.116)$ & \\
pN2 & $2.712(2.216-3.319)$ & \\
pN3 & $6.940(3.363-14.322)$ & \\
Pathologic pleural involvement & & .012 \\
p0 & & \\
p1 & $1.334(1.103-1.613)$ & \\
p2 & $1.231(0.950-1.596)$ & \\
p3 & $1.378(1.023-1.858)$ & \\
Lymphatic permeation (positive vs & $1.299(1.104-1.528)$ & .002 \\
negative) & & \\
Vascular invasion (positive vs negative) & $1.384(1.146-1.671)$ & .001 \\
Pre-PLC (positive vs negative) & $1.544(1.079-2.207)$ & .017 \\
Post-PLC (positive vs negative) & $1.769(1.250-2.504)$ & .001 \\
\hline CEA,Carcinoembryonic antigen; $C I$, confidence interval; $P L C$, pleural lavage cytology. \\
\end{tabular}

$C E A$, Carcinoembryonic antigen; $C I$, confidence interval; $P L C$, pleural lavage cytology.

resections. Most reports on PLC studied only pre-PLC, ${ }^{2,6-15}$ and only 6 reports, ${ }^{6,7,9,16,17}$ including our previous report, ${ }^{2}$ evaluated post-PLC. Although PLC after radical NSCLC resection and before chest closure (post-PLC) has also been appreciated by many studies including a recent meta-analysis, ${ }^{18}$ the comparative significance of pre- and post-PLC remains controversial.

In 2006, we reported an analysis on pre-PLC and postPLC in relation to pathologic TNM factors on a multivariate basis in a large cohort of almost 1200 patients accumulated before March $2001 .^{2}$ We concluded pre- and post-PLC should be recognized as essential prognostic factors and should be performed in patients with NSCLC without pleural effusion or dissemination. We also concluded that post-PLC, compared with pre-PLC, had a greater and independent impact on survival and should be incorporated in the pathologic staging of NSCLC. We continued accumulating patients, and the number of patients has exceeded 2000, the largest single-institution experience ever studied on PLC.

The reported positive rates of pre-PLC and post-PLC in the literature range from $3.2 \%$ to $22.6 \%$ (median: $7.8 \%$ ) and from $4.6 \%$ to $13.5 \%$ (median: $9.8 \%$ ) and were $3.0 \%$ and $3.2 \%$ in this study, respectively. The steady increase in patients with early lung cancer in our cohort may explain the low rates in our study. Although the rates were low, the large cohort enabled us to accumulate patients with positive PLC sufficient to evaluate the significance of PLC.
TABLE 4. Multivariate analysis for factors predictive of recurrencefree survival

\begin{tabular}{|c|c|c|}
\hline Variables & $\begin{array}{l}\text { Hazard ratio } \\
(\mathbf{9 5} \% \mathbf{C I})\end{array}$ & $\begin{array}{c}P \\
\text { value }\end{array}$ \\
\hline Age $(\geq 66$ vs $<66)$ & $1.176(1.017-1.361)$ & .029 \\
\hline $\begin{array}{l}\text { Differentiation } \\
\quad \text { Well }\end{array}$ & & .024 \\
\hline Moderately & $1.286(1.031-1.605)$ & \\
\hline Poorly & $1.421(1.102-1.833)$ & \\
\hline $\begin{array}{l}\text { Pathologic T classification } \\
\text { pT1 }\end{array}$ & & .006 \\
\hline pT2 & $1.367(1.138-1.641)$ & \\
\hline pT3 & $1.126(0.768-1.650)$ & \\
\hline pT4 & $1.323(1.002-1.746)$ & \\
\hline $\begin{array}{l}\text { Pathologic } \mathrm{N} \text { classification } \\
\text { pNO }\end{array}$ & & $<.001$ \\
\hline pN1 & $1.711(1.388-2.109)$ & \\
\hline $\mathrm{pN} 2$ & $3.222(2.640-3.932)$ & \\
\hline $\mathrm{pN} 3$ & $6.303(2.890-13.744)$ & \\
\hline $\begin{array}{l}\text { Pathologic pleural involvement } \\
\text { p0 }\end{array}$ & & .001 \\
\hline $\mathrm{p} 1$ & $1.238(1.022-1.500)$ & \\
\hline $\mathrm{p} 2$ & $1.604(1.255-2.050)$ & \\
\hline p3 & $1.398(1.033-1.892)$ & \\
\hline $\begin{array}{l}\text { Lymphatic permeation (positive vs } \\
\text { negative) }\end{array}$ & $1.184(1.010-1.389)$ & .038 \\
\hline Vascular invasion (positive vs negative) & $1.442(1.197-1.738)$ & $<.001$ \\
\hline Pre-PLC (positive vs negative) & $1.453(1.018-2.073)$ & .040 \\
\hline Post-PLC (positive vs negative) & $2.552(1.829-3.560)$ & $<.001$ \\
\hline
\end{tabular}

$C I$, Confidence interval; $P L C$, pleural lavage cytology.

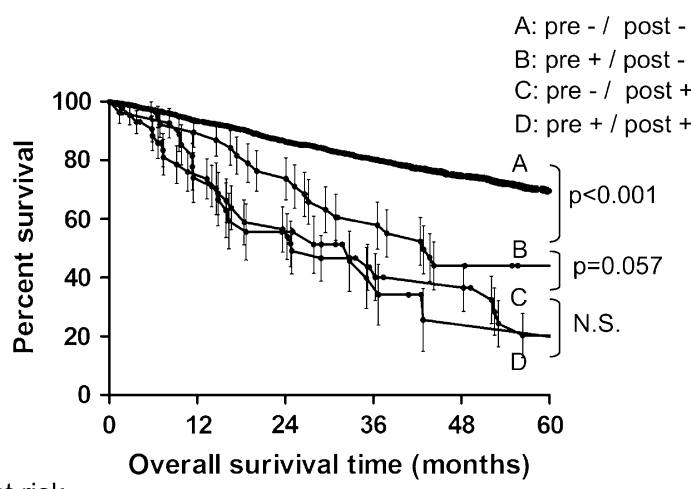

Patients at risk

$\begin{array}{ccccccc}\text { A } & 2070 & 1921 & 1733 & 1402 & 1184 & 955 \\ \text { B } & 38 & 35 & 30 & 22 & 17 & 15 \\ \text { C } & 43 & 32 & 24 & 13 & 12 & 6 \\ \text { D } & 27 & 21 & 15 & 7 & 4 & 4\end{array}$

FIGURE 4. The Kaplan-Meier curves of 4 groups: pre-PLC-/post-PLC-, pre-PLC + /post-PLC-, pre-PLC-/post-PLC + , pre-PLC + post-PLC + . The survivals were similarly poor for positive post-PLC groups regardless of prePLC results and were significantly worse than negative post-PLC groups. The fine vertical bars in each graph indicate the standard error for each data point. $P L C$, Pleural lavage cytology. 


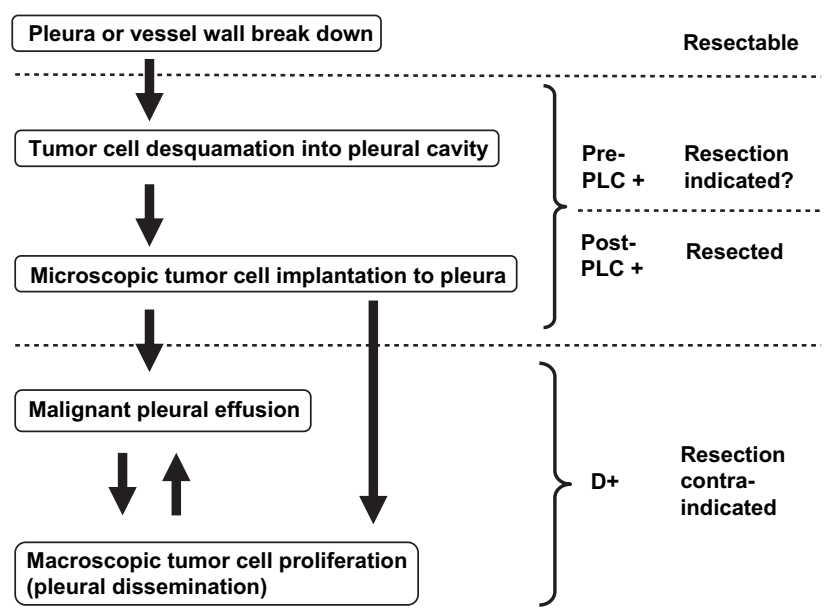

FIGURE 5. Mechanism of pleural dissemination. Macroscopic pleural dissemination is an indicator to discontinue resection, but it is not clear how to deal with patients with positive pre-PLC. PLC, Pleural lavage cytology.

Pre-PLC results can be obtained before lung resection. A positive pre-PLC result in a patient without pleural dissemination or effusion indicates microscopic intrapleural cancer cell spread through broken-down pleura or permeated vessels (Figure 5). Although macroscopic pleural dissemination is an indicator to discontinue resection because of poor outcome even after lung resection, our analyses showed patients with positive pre-PLC fared better than to contraindicate lung resection. When analyzed together with other prognostic factors obtainable after lung resection including pre-PLC result, the hazard ratios of positive pre-PLC result were lower than those of positive post-PLC results. The survival curves revealed positive pre-PLC results had less impact on survival than did positive post-PLC results (Figure 4). The intermediate survival group (B: pre + post-) resulted in 5 -year survival rates of $51 \%$, which suggests this group may have benefited from adjuvant chemotherapy, and prePLC is of certain value. However, only after resection is positive pre-PLC result necessary in indicating adjuvant therapy. Positive pre-PLC results did not contraindicate surgical resection, either. There is no need to obtain pre-PLC results before resection, and their intraoperative diagnoses are not necessary.

Post-PLC results are obtained only after lung resection and therefore have no impact on surgical indications. Although positive results correlated with advanced cancer status, univariate and multivariate analyses proved post-PLC was an independent prognostic factor, as we previously reported. ${ }^{2}$ A positive post-PLC result had an extremely strong impact on overall survival; its hazard ratio was higher than that of pathologic T4 status. Its impact on recurrence-free survival was also strong; its hazard ratio was the highest among the analyzed factors other than $\mathrm{pN} 2$ or $\mathrm{pN} 3$. Only 1 $(1.4 \%)$ among 70 patients with positive post-PLC survived without recurrence for more than 5 years.
Last year, the seventh edition of the TNM classification of lung cancer was proposed. ${ }^{19-21}$ Pleural dissemination (malignant pleural effusion and pleural nodules) was reclassified from T4 to M1a, but intraoperative PLC was not incorporated in the proposal. Our data showed positive post-PLC patient survival was almost equal to pathologic T4 (other than by additional nodules or pleural dissemination) patient survival as reported in the proposal (5-year survival rate: $22 \%) .{ }^{19}$ Patients with a positive post-PLC had a marginally, but not significantly, better survival compared with patients with dissemination. This might indicate that the tumor burden in patients with positive post-PLC was less than that in patients with dissemination. However, because almost all patients with positive post-PLC had disease recurrence within 5 years, we need to classify them as early dissemination status and treat them in the same way as dissemination patients.

\section{CONCLUSION}

Pre-PLC is of less value in clinical practice, but patients with positive pre-PLC may require adjuvant chemotherapy. A positive post-PLC result was a strong unfavorable prognostic factor, and almost all patients with positive postPLC relapsed within 5 years. We propose that positive post-PLC disease should be classified to pathologic T4 and managed similarly to dissemination.

We thank Professor J. Patrick Barron of the International Medical Communications Center of Tokyo Medical University for his review of this manuscript.

\section{References}

1. Spjut HJ, Hendrix VJ, Ramirez GA, Roper CL. Carcinoma cells in pleural cavity washings. Cancer. 1958;11:1222-5.

2. Enatsu S, Yoshida J, Yokose T, Nishimura M, Nishiwaki Y, Shirakusa T, et al. Pleural lavage cytology before and after lung resection in non-small cell lung cancer patients. Ann Thorac Surg. 2006;81:298-304.

3. Travis W, Coblby T, Corrin B, Shimosato Y, Brambilla E. Pathology and genetics of tumours of the lung, pleura, thymus and heart. 3rd ed. Berlin: Springer Verlag; 1999.

4. UICC. TNM classification of malignant tumours, 5th and 6th eds. Geneva: UICC; 1997 and 2002.

5. The Japan Lung Cancer Society. General rule for clinical and pathological record of lung cancer [in Japanese]. 6th ed. Tokyo: Kanehara; 2003.

6. Kjellberg SI, Dresler CM, Goldberg M. Pleural cytologies in lung cancer without pleural effusions. Ann Thorac Surg. 1997;64:941-4.

7. Higashiyama M, Doi O, Kodama K, Yokouchi H, Tateishi R, Horai T, et al. Pleural lavage cytology immediately after thoracotomy and before closure of the thoracic cavity for lung cancer without pleural effusion and dissemination: clinicopathologic and prognostic analysis. Ann Surg Oncol. 1997;4:409-15.

8. Hillerdal G, Dernevik L, Almgren SO, Kling PA, Gustafsson G. Prognostic value of malignant cells in pleural lavage at thoracotomy for bronchial carcinoma. Lung Cancer. 1998;21:47-52.

9. Dresler CM, Fratelli C, Babb J. Prognostic value of positive pleural lavage in patients with lung cancer resection. Ann Thorac Surg. 1999;67:1435-9.

10. Ichinose Y, Tsuchiya R, Yasumitsu T, Koike T, Yamato Y, Nakagawa K, et al Prognosis of non-small cell lung cancer patients with positive pleural lavage cytology after a thoracotomy: results of the survey conducted by the Japan Clinical Oncology Group. Lung Cancer. 2001;31:37-41.

11. Okada M, Sakamoto T, Nishio W, Uchino K, Tsuboshima K, Tsubota N. Pleura lavage cytology in non-small cell lung cancer: lessons from 1000 consecutive resections. J Thorac Cardiovasc Surg. 2003;126:1911-5.

12. Lim E, Ali A, Theodorou P, Nicholson AG, Ladas G, Goldstraw P. Intraoperative pleural lavage cytology is an independent prognostic indicator for staging nonsmall cell lung cancer. J Thorac Cardiovasc Surg. 2004;127:1113-8. 
13. Vicidomini G, Santini M, Fiorello A, Parascandolo V, Calabro B, Pastore V. Intraoperative pleural lavage: is it a valid prognostic factor in lung cancer? Ann Thorac Surg. 2005;79:254-7; discussion 257.

14. Satoh Y, Hoshi R, Ishikawa Y, Horai T, Okumura S, Nakagawa K. Recurrence patterns in patients with early stage non-small cell lung cancers undergoing positive pleural lavage cytology. Ann Thorac Surg. 2007;83:197-202.

15. Nakagawa T, Okumura N, Kokado Y, Miyoshi K, Matsuoka T, Kameyama K. Clinical relevance of intraoperative pleural lavage cytology in non-small cell lung cancer. Ann Thorac Surg. 2007;83:204-8.

16. Kotoulas C, Lazopoulos G, Karaiskos T, Tomos P, Konstantinou M, Papamichalis G, et al. Prognostic significance of pleural lavage cytology after resection for non-small cell lung cancer. Eur J Cardiothorac Surg. 2001;20:330-4.

17. Eagan RT, Bernatz PE, Payne WS, Pairolero PC, Williams DE, Goellner JR, et al. Pleural lavage after pulmonary resection for bronchogenic carcinoma. $J$ Thorac Cardiovasc Surg. 1984;88:1000-3.
18. Li YN, Shi HZ, Liang QL, Yang HB, Huang GM. Prognostic significance of pleural lavage cytology in patients with lung cancer: a meta-analysis. Lung Cancer. 2008;60:183-92.

19. Rami-Porta R, Ball D, Crowley J, Giroux DJ, Jett J, Travis WD, et al. The IASLC Lung Cancer Staging Project: proposals for the revision of the T descriptors in the forthcoming (seventh) edition of the TNM classification for lung cancer. $J$ Thorac Oncol. 2007;2:593-602.

20. Goldstraw P, Crowley J, Chansky K, Giroux DJ, Groome PA, Rami-Porta R, et al. The IASLC Lung Cancer Staging Project: proposals for the revision of the TNM stage groupings in the forthcoming (seventh) edition of the TNM Classification of malignant tumours. J Thorac Oncol. 2007;2:706-14.

21. Postmus PE, Brambilla E, Chansky K, Crowley J, Goldstraw P, Patz EF Jr, et al. The IASLC Lung Cancer Staging Project: proposals for revision of the M descriptors in the forthcoming (seventh) edition of the TNM classification of lung cancer. J Thorac Oncol. 2007;2:686-93. 
TABLE E1. Univariate analysis of clinicopathologic factors including those available after lung resection for overall and recurrence-free survival $(\mathbf{n}=\mathbf{2 1 7 8})$

\begin{tabular}{|c|c|c|c|}
\hline Factors & $\mathbf{n}$ & OS $P$ value $\dagger$ & RFS $\boldsymbol{P}$ value $\dagger$ \\
\hline \multicolumn{4}{|l|}{ Age $(y)^{*}$} \\
\hline$<66$ & 1086 & & \\
\hline$\geq 66$ & 1092 & $<.001$ & .017 \\
\hline \multicolumn{4}{|l|}{ Sex } \\
\hline Male & 1389 & & \\
\hline Female & 792 & $<.001$ & $<.001$ \\
\hline \multicolumn{4}{|l|}{ Smoking history } \\
\hline Never smoker & 687 & & \\
\hline Current/previous smoker & 1472 & $<.001$ & $<.001$ \\
\hline \multicolumn{4}{|l|}{ CEA level (ng/mL) } \\
\hline$<5.0$ & 1287 & & \\
\hline$\geq 5.0$ & 875 & $<.001$ & $<.001$ \\
\hline \multicolumn{4}{|l|}{ Pre-PLC } \\
\hline Positive & 65 & & \\
\hline Negative & 2113 & $<.001$ & $<.001$ \\
\hline \multicolumn{4}{|l|}{ Post-PLC } \\
\hline Positive & 70 & & \\
\hline Negative & 2108 & $<.001$ & $<.001$ \\
\hline \multicolumn{4}{|l|}{ Resection type } \\
\hline Lobectomy & 2067 & & \\
\hline Pneumonectomy & 111 & $<.001$ & $<.001$ \\
\hline \multicolumn{4}{|l|}{ Histology } \\
\hline Adenocarcinoma & 1503 & & \\
\hline Others & 675 & $<.001$ & .010 \\
\hline \multicolumn{4}{|l|}{ Differentiation } \\
\hline Well & 583 & & \\
\hline Moderately & 1055 & & \\
\hline Poorly & 479 & $<.001$ & $<.001$ \\
\hline \multicolumn{4}{|l|}{ Pathologic T status } \\
\hline pT1 & 1043 & & \\
\hline pT2 & 857 & & \\
\hline pT3 & 140 & & \\
\hline pT4 & 138 & $<.001$ & $<.001$ \\
\hline \multicolumn{4}{|l|}{ Pathologic N status } \\
\hline $\mathrm{pNO}$ & 1544 & & \\
\hline $\mathrm{pN} 1$ & 332 & & \\
\hline $\mathrm{pN} 2$ & 294 & & \\
\hline $\mathrm{pN} 3$ & 8 & $<.001$ & $<.001$ \\
\hline \multicolumn{4}{|l|}{ Pathologic stage } \\
\hline I & 1414 & & \\
\hline II & 316 & & \\
\hline III & 433 & & \\
\hline IV & 15 & $<.001$ & $<.001$ \\
\hline \multicolumn{4}{|l|}{ Pathologic P status } \\
\hline p0 & 1389 & & \\
\hline $\mathrm{p} 1$ & 378 & & \\
\hline $\mathrm{p} 2$ & 161 & & \\
\hline p3 & 191 & $<.001$ & $<.001$ \\
\hline \multicolumn{4}{|l|}{ Lymphatic permeation } \\
\hline Positive & 685 & & \\
\hline Negative & 1488 & $<.001$ & $<.001$ \\
\hline
\end{tabular}

TABLE E1. Continued

\begin{tabular}{|c|c|c|c|}
\hline Factors & $\mathbf{n}$ & OS $P$ value $\dagger$ & RFS $P$ value $\dagger$ \\
\hline \multicolumn{4}{|l|}{ Vascular invasion } \\
\hline Positive & 1096 & & \\
\hline Negative & 1075 & $<.001$ & $<.001$ \\
\hline
\end{tabular}

